\title{
Postmortem blood concentrations of sartans measured by liquid chromatography-tandem mass spectrometry
}

\section{Ranta, Merja}

2016-07

Ranta , M \& Ketola , R 2016 , ' Postmortem blood concentrations of sartans measured by liquid chromatography-tandem mass spectrometry ' , Forensic toxicology , vol. 34 , no. 2 , pp. 235-243 . https://doi.org/10.1007/s11419-016-0308-y

http://hdl.handle.net/10138/224095

https://doi.org/10.1007/s11419-016-0308-y

publishedVersion

Downloaded from Helda, University of Helsinki institutional repository.

This is an electronic reprint of the original article.

This reprint may differ from the original in pagination and typographic detail.

Please cite the original version. 


\title{
Postmortem blood concentrations of sartans measured by liquid chromatography-tandem mass spectrometry
}

\author{
Merja Gergov ${ }^{1,2} \cdot$ Raimo A. Ketola $^{1,2}$ (I)
}

Received: 1 December 2015/Accepted: 7 February 2016/Published online: 2 March 2016

(C) Japanese Association of Forensic Toxicology and Springer Japan 2016

\begin{abstract}
A liquid chromatography-tandem mass spectrometric (LC-MS/MS) method was developed and validated for the analysis of seven common sartans (candesartan, eprosartan, losartan, olmesartan, telmisartan, valsartan, and losartan carboxylic acid (EXP3174), the active metabolite of losartan) in postmortem blood samples with liquid-liquid extraction. Detection was accomplished by triple-quadrupole MS in the selected reaction monitoring mode. The validation procedure showed low limits of quantitation of $5 \mathrm{ng} / \mathrm{mL}$ for all compounds with good accuracy and precision. The matrix effect was evaluated from the variation of peak areas and concentrations. The method shows some matrix effect but the effect was efficiently compensated by using an internal standard method. The method was applied to the analysis of sartans in postmortem blood samples, and produced 534 positive findings during 2014-2015. Nine deaths were encountered where the concentration of a sartan was very high, indicating intoxication together with other causes of death or multi-drug intoxication. The quantitative results indicate that sartans do not show significant postmortem redistribution; thus concentrations higher than the therapeutic range can be considered as being toxic or fatal.
\end{abstract}

Raimo A. Ketola

raimo.ketola@thl.fi

1 Department of Forensic Medicine, Faculty of Medicine, University of Helsinki, Kytösuontie 11, 00014 Helsinki, Finland

2 Present Address: Forensic Toxicology Unit, National Institute for Health and Welfare (THL), P.O. Box 30, 00271 Helsinki, Finland
Keywords Sartans - Angiotensin II receptor antagonists . LC-MS/MS · Postmortem · Blood concentration

\section{Introduction}

Sartans are nonpeptidergic angiotensin II receptor antagonists, which are used in the treatment of cardiovascular diseases as they modulate the renin-angiotensin-aldosterone system $[1,2]$. They include the following (in their use in Finland): candesartan (Atacand, Candemox, Candesartan, Candestad, Candexetil), eprosartan (Teveten, Eprozar), losartan (Cozaar, Losartan, Losatrix), olmesartan (Benetor, Olmetec), telmisartan (Kinzalmono, Kinzalcomb, Micardis, Telmisartan, Tolura), and valsartan (Diovan, Valsartan). Sartans are used alone or in combination with other classes of antihypertensives such as hydrochlorothiazide for the treatment of hypertension. Sartans are also used in the treatment of diabetic nephropathy, the treatment of hypertensive patients with type 2 diabetes mellitus, and in the treatment of congestive heart failure.

Different sartans used in therapy have quite similar adverse reactions, which include diarrhea, muscle pain, dizziness, insomnia, headache, weakness, and palpitations. There are several case reports of serious adverse reactions and/or acute toxicity that result from treatments with ingestion of sartans. For instance, a 70-year old woman developed a reversible psychosis after 2 days of losartan therapy [3], and a 46-year old man manifested acute hepatic injury after 3-4 weeks of losartan therapy [4]. In one noteworthy case, oligohydramnios was found in a woman at 29 weeks of gestation after olmesartan therapy, although her fetus had normal kidneys on ultrasound evaluation. Withdrawal of olmesartan medoxomil, maternal rehydration, and a single dose of furosemide reversed the renal 
impairment. After the delivery, the neonate was confirmed to have normal renal function. This case indicated that fetal renal impairment due to olmesartan medoxomil may be reversible [5]. A study of 185 adult referrals to poison control centers for valsartan ingestion, reported that only $7 \%$ of the cases were judged to be serious [6]. The manifestations of the poisonings included dizziness, drowsiness, bradycardia/tachycardia and hypotension/ hypertension [6]. Two overdose cases have also been reported. The first case was a 19-year-old healthy woman who ingested 25 tablets of valsartan $(80 \mathrm{mg})$ [7]. Three hours after the ingestion, her blood pressure fell to $70 / 40 \mathrm{mmHg}$ and her pulse increased to $111 / \mathrm{min}$. The refractory hypotension was successfully treated with naloxone and vasopressin. The second overdose case was a 77-year-old man who ingested a $2240 \mathrm{mg}$ overdose of candesartan exhibited abdominal pain and a marked increase in serum amylase levels, consistent with acute pancreatitis but the symptoms were resolved within 2 days [8]. However, fatal sartan overdoses have not yet been reported.

Analytical techniques and methods used for the determination of sartans in various types of samples have been recently reviewed by Muszalska et al. [9]. In most methods used for the measurement of the compounds and metabolites in human plasma only one or two compounds have been analyzed sporadically. Such analyses typically used high or ultra-high performance liquid chromatography (HPLC or UHPLC) with mass spectrometric (MS), ultraviolet (UV) or fluorescence detection. The lower limits of quantitation (LLOQs) for MS detection ranged from 0.2 to $60 \mathrm{ng} / \mathrm{mL}$. There are several articles that present an analytical method for a mixture of sartans, usually four different sartans [10-17]. The LLOQs for specific sartans in human plasma for the methods used in these studies ranged from sub $\mathrm{ng} / \mathrm{mL}$ to approximately $400 \mathrm{ng} / \mathrm{mL}$. Dresen et al. [12] reported the lowest LLOQs for a mixture of sartans that ranged from $0.62 \mathrm{ng} / \mathrm{mL}$ for telmisartan to $9.1 \mathrm{ng} / \mathrm{mL}$ for eprosartan. These authors used an AB Sciex 3200 QTRAP liquid chromatography-tandem mass spectrometry (LC-MS/MS) system. Kristoffersen et al. [18] presented the analysis of sartans in postmortem (PM) blood. They studied 14 cardiovascular drugs including six beta-blockers, three calcium-channel antagonists, one antiarrythmic drug, and four sartans (losartan, irbesartan, telmisartan, and valsartan) in whole blood at therapeutic and toxic levels, which were simultaneously determined by LC/MS. The LLOQs in that study were, however, rather high as they ranged from $29 \mathrm{ng} / \mathrm{mL}$ for telmisartan to $448 \mathrm{ng} / \mathrm{mL}$ for valsartan. PM concentrations in the whole blood were not reported in any of other studies.

The aim of this research was to develop a sensitive LCMS/MS method for the simultaneous analysis of six sartans available in Finland (candesartan, eprosartan, losartan, olmesartan, telmisartan, and valsartan) and losartan carboxylic acid (EXP3174), the active metabolite of losartan, in samples taken from PM whole blood. A further aim was to determine typical PM concentrations of these compounds in the whole blood in respect to their therapeutic ranges.

\section{Materials and methods}

\section{Materials}

Candesartan, eprosartan, and olmesartan were purchased from Santa Gruz Biotechnology Inc. (Santa Cruz, CA, USA). Telmisartan was supplied by Boehringer (Ingelheim, Germany); losartan potassium was obtained from Chiron (Källby, Sweden); losartan carboxylic acid (EXP3174) was supplied by Cayman Chemical (Ann Arbor, MI, USA), and valsartan was obtained from Novartis International (Ringaskiddy, Ireland). The internal standard diazepam- $d_{5}$ was obtained from LGC (Luckenwalde, Germany), and the second internal standard enalapril maleate was bought from Merck (Darmstad, Germany). LC-MS Chromasolv grade methanol was purchased from Sigma-Aldrich (Steinheim, Germany), and the analytical reagent grade butyl acetate obtained from Sigma-Aldrich (St. Louis, MO, USA). Other common solvents and reagents were supplied by Merck (Darmstadt, Germany) and all were of analytical grade. Water was purified using a Milli-Q Integral 5 (Millipore, Bedford, MA, USA). Bovine whole blood (Järvi-Suomen Portti Oy, Mikkeli, Finland) served as the calibration medium for the method development.

\section{Samples}

The PM intervals from deaths to autopsies were on average 5 days, and on arrival at the morgues the cadavers were kept in cold storage $\left(+3-5^{\circ} \mathrm{C}\right)$ pending autopsies. The concentration data were acquired from femoral venous blood taken at autopsies. The samples, containing $1 \% \mathrm{NaF}$ to prevent microbial processes, were stored at $+4{ }^{\circ} \mathrm{C}$ until and during the laboratory investigation.

\section{Reference Standard solutions}

Separate stock solutions of the analytes were prepared in methanol at the concentration of $1.0 \mathrm{mg} / \mathrm{mL}$ of a free compound. A standard mixture that contained all seven analytes was made from the stock solutions to obtain concentration of $0.1 \mathrm{mg} / \mathrm{mL}$ of the analytes. Working mixtures were diluted from the standard mixture in 
methanol/water $(1 / 1, \mathrm{v} / \mathrm{v})$. Diazepam- $d_{5}$ and enalapril were used as internal standards, and the appropriate volumes of the internal standard solutions were added to blood samples to obtain concentrations of $50 \mathrm{ng} / \mathrm{mL}$ of diazepam- $d_{5}$ and $100 \mathrm{ng} / \mathrm{mL}$ of enalapril in the sample material. The calibration range in PM studies was $5-1000 \mathrm{ng} / \mathrm{mL}$ for all analytes. PM samples of whole blood with concentrations that exceeded the upper value of the calibration range were re-analyzed after the appropriate dilution.

\section{Extraction procedure}

The extraction was carried out in two steps. Blood samples (1 mL) were first spiked with the internal standard diazepam- $d_{5}(50 \mu \mathrm{L}, 1 \mu \mathrm{g} / \mathrm{mL})$, and mixed with $1 \mathrm{ml}$ of Trisbuffer (pH 7.0). A 60-mg quantity of $\mathrm{NaCl}$ was added, and samples were spun in a vortex-mixer $(2 \mathrm{~min})$, then extracted with $1 \mathrm{ml}$ of butyl acetate. The resulting organic layer was separated by centrifuging (4330 $\mathrm{g}, 5 \mathrm{~min}$ ), and transferred to another tube and evaporated to dryness in a water bath $\left(40{ }^{\circ} \mathrm{C}\right)$ under a nitrogen flow. The residue was reconstituted by adding $60 \mu \mathrm{L}$ methanol and $90 \mu \mathrm{L}$ of ammonium acetate buffer $(10 \mathrm{mmol} / \mathrm{L}, 0.1 \%$ formic acid, $\mathrm{pH}$ 3.2). Samples were then vortexed and sonicated for $5 \mathrm{~min}$. After centrifugation $(4330 \mathrm{~g}, 5 \mathrm{~min}), 50 \mu \mathrm{L}$ of the extract was transferred to an autosampler vial equipped with a $300 \mu \mathrm{L}$ insert. In the second extraction step, the acidic internal standard (enalapril $10 \mu \mathrm{L}, 10 \mu \mathrm{g} / \mathrm{mL}$ ) was added to the rest of the blood $(1 \mathrm{~mL})$, to which $600 \mu \mathrm{L}$ of phosphoric acid $(8.5 \%)$ and $500 \mu \mathrm{L}$ phosphate buffer were added to give acidic $\mathrm{pH}$. Extraction was carried out in a bench top shaker $\left(250 \mathrm{~min}^{-1}\right)$ with $5 \mathrm{~mL}$ of dichloromethane/isopropanol (95:5, v/v). The layers were separated after $30 \mathrm{~min}$ by centrifugation (4330 $\mathrm{g}, 5 \mathrm{~min})$, and the organic lower layer was separated and evaporated to dryness in a water bath $\left(40{ }^{\circ} \mathrm{C}\right)$ under a nitrogen flow. The residue was reconstituted with a mixture of $60 \mu \mathrm{L}$ methanol and $90 \mu \mathrm{L}$ of ammonium acetate buffer $(10 \mathrm{mmol} / \mathrm{L}$, $0.1 \%$ formic acid, $\mathrm{pH}$ 3.2). Samples were then vortexed and sonicated for $5 \mathrm{~min}$. The samples were centrifuged (4330 $\mathrm{g}, 5 \mathrm{~min}$ ), after which a $50 \mu \mathrm{L}$ of the extract was combined with the first extract in the autosampler vial.

\section{Instrumentation and analysis}

The LC separations were carried out using a Shimadzu Prominence HPLC system that consisted of two LC-20AD pumps, an SIL-20AHT autosampler, a DGU-20A5 vacuum degasser, and a CTO-20A column oven (Shimadzu USA Manufacturing Inc., Canby, OR, USA). A Phenomenex Gemini-NX column and a Phenomenex C18 guard column $(4 \times 2 \mathrm{~mm})$ were used in chromatographic separations $(100 \times 2.1 \mathrm{~mm} ; 4 \mu \mathrm{m}$, Phenomenex, Torrance, CA, USA).
The mass spectrometric analysis was performed using an Applied Biosystems/Sciex 4000 QTRAP ${ }^{\circledR}$ LC-MS/MS instrument equipped with a Turbo $\mathrm{V}^{\mathrm{TM}}$ source and a TurboIonSpray ${ }^{\circledR}$ probe (Applied Biosystems, Concord, ON, Canada). The software used was Analyst 1.5.1 (Sciex, Framingham, MA, USA).

\section{Liquid chromatography}

The analytical column was stabilized at $35^{\circ} \mathrm{C}$. The mobile phase gradient consisted of methanol and ammonium acetate buffer (both containing $0.1 \%$ formic acid) as follows: the methanol proportion was held at $40 \%$ during the equilibrium time of $7 \mathrm{~min}$. After injection, the methanol proportion was increased to $70 \%$ for $10 \mathrm{~min}$, then to $95 \%$ for $5 \mathrm{~min}$, then it was kept at $95 \%$ for $5 \mathrm{~min}$ to clean the column, and finally decreased back to $40 \%$ for $2 \mathrm{~min}$. The total flow rate through the column was $0.3 \mathrm{~mL} / \mathrm{min}$, and the total run time was $29 \mathrm{~min}$. The injection volume was $20 \mu \mathrm{L}$.

\section{Mass spectrometry}

The total flow from the LC was directed to the ion source without splitting. The needle voltage was $5.2 \mathrm{kV}$ and the ion spray heater temperature was $475{ }^{\circ} \mathrm{C}$. The curtain gas (nitrogen) was set at 12 (arbitrary units) and collision gas (nitrogen) pressure in the collision cell was set at 10 (arbitrary units) by the Analyst software. The nebulizer gas (nitrogen) was set at $40 \mathrm{psi}(276 \mathrm{kPa})$ and turbo heater gas (nitrogen) at $60 \mathrm{psi}(414 \mathrm{kPa})$. The optimum values for collision energy, declustering potential, and cell entrance potential were optimized for each compound. A selected reaction monitoring $(\mathrm{SRM})$ mode was used for monitoring three ion transitions for each analyte and one for the internal standards (Table 1). A dwell time of $50 \mathrm{~ms}$ was used for all transitions.

\section{Validation}

Validation of the method included the determination of selectivity/specificity, linearity range, limit of detection (LOD), the LLOQ and upper limit of quantitation (ULOQ), accuracy, within and between sample precision, and combined variation from matrix effects. Recovery of the extraction was not determined but determinations of precision together with satisfactorily low LLOQs were regarded as more useful in the validation. The validation experiments were performed by spiking bovine blood and PM blood samples with all six compounds. Three replicates of sample preparation and analysis were performed at each test. 
Fig. 1 Selected reaction monitoring chromatograms of sartans in the calibration standard mixture at $10 \mathrm{ng} / \mathrm{mL}$ in blank whole blood. The second peak in the trace $\mathrm{m} / \mathrm{z}$ $437 \rightarrow 235$ for EXP3174 is a fragment of valsartan
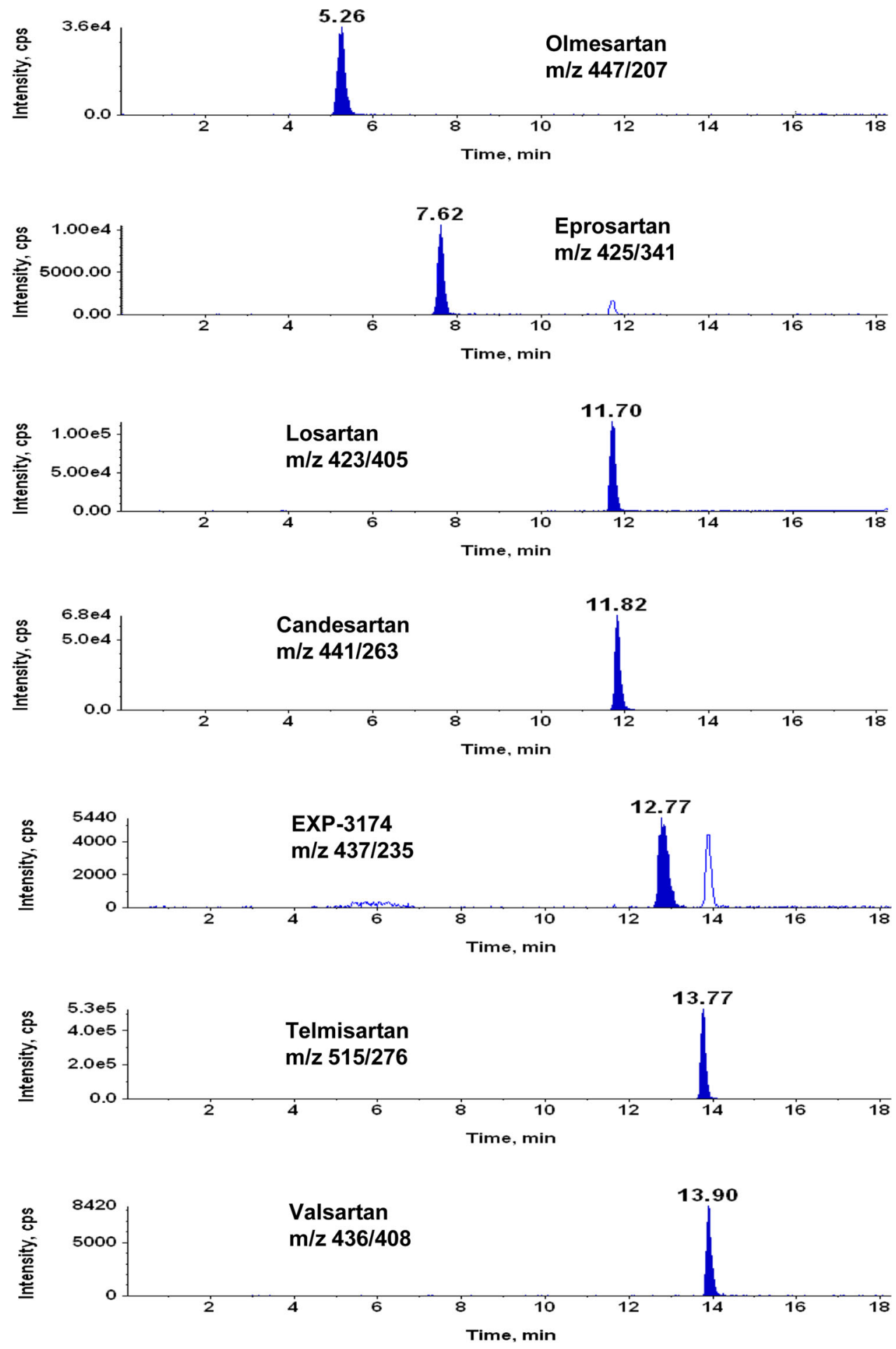

\section{Selectivity/specificity}

Selectivity was ensured by running the instrument in the SRM mode. No extra peaks in the blank blood samples in this mode setting were observed for any of the SRM transitions (Fig. 1). Selectivity in authentic PM blood samples was checked in 40 samples previously known to be positive for one sartan, but negative for other sartans, and eventually containing other drugs. Initially, the lack of interfering signals was regarded as proof of selectivity. 
Table 1 Optimized ion transitions, collision energies, and retention times of seven sartans, and the internal standards diazepam- $d_{5}$ and enalapril

\begin{tabular}{|c|c|c|c|c|c|c|c|}
\hline \multirow[t]{2}{*}{ Analyte } & \multirow[t]{2}{*}{$\begin{array}{l}\text { Precursor ion } \\
{[\mathrm{M}+\mathrm{H}]^{+}(\mathrm{m} / \mathrm{z})}\end{array}$} & \multirow[t]{2}{*}{$\begin{array}{l}\text { Declustering } \\
\text { potential (V) }\end{array}$} & \multirow[t]{2}{*}{$\begin{array}{l}\text { Target product ion } 1 \\
(\mathrm{~m} / \mathrm{z})\end{array}$} & \multirow[t]{2}{*}{$\begin{array}{l}\mathrm{CE} \\
(\mathrm{eV})\end{array}$} & \multicolumn{2}{|c|}{$\begin{array}{l}\text { Qualifier product ions } \\
(\mathrm{m} / \mathrm{z})\end{array}$} & \multirow[t]{2}{*}{$\begin{array}{l}\text { Retention time } \\
\text { (min) }\end{array}$} \\
\hline & & & & & $\begin{array}{l}\text { Ion } 2 / \mathrm{CE} \\
(\mathrm{eV})\end{array}$ & $\begin{array}{l}\text { Ion } 3 / \mathrm{CE} \\
(\mathrm{eV})\end{array}$ & \\
\hline Olmesartan & 447 & 50 & 207 & 40 & $190 / 60$ & $429 / 20$ & 5.2 \\
\hline Eprosartan & 425 & 50 & 341 & 35 & $207 / 35$ & $135 / 50$ & 7.6 \\
\hline Losartan & 423 & 70 & 405 & 20 & $207 / 30$ & $377 / 20$ & 11.7 \\
\hline Candesartan & 441 & 50 & 263 & 20 & $235 / 30$ & $423 / 20$ & 11.8 \\
\hline Telmisartan & 515 & 100 & 276 & 70 & $305 / 40$ & $497 / 50$ & 13.8 \\
\hline Valsartan & 436 & 60 & 408 & 10 & $362 / 20$ & $291 / 25$ & 13.9 \\
\hline EXP3174 & 437 & 60 & 235 & 35 & $207 / 35$ & $190 / 35$ & 12.8 \\
\hline Diazepam- $d_{5}$ & 290 & 90 & 198 & 40 & - & - & 12.2 \\
\hline Enalapril & 377 & 30 & 234 & 35 & - & - & 5.9 \\
\hline
\end{tabular}

$C E$ collision energy

\section{Working range and limits of quantitation}

Criteria for the LLOQ and ULOQ were established as the lowest and highest concentration fulfilling the following criteria: (1) bias from the calibration curve less than $20 \%$, (2) relative standard deviation (RSD) of three replicates less than $20 \%$, and (3) signal-to-noise $>10$. A working range was defined as the linear range starting from LLOQ and ending up at ULOQ, and was measured by plotting the peak area ratio of the analyte to the internal standard versus the analyte concentration. The following criteria were applied: quadratic regression $(1 / x)$ with a correlation coefficient higher than 0.997 , bias from the calibration plot less than $20 \%$ for all individual calibration points, and an RSD of three replicates less than $20 \%$.

\section{Precision and accuracy}

The quantitation was based on internal standards. Precision and accuracy were initially evaluated as mean values over the tested concentration range $(3-3000 \mathrm{ng} / \mathrm{mL})$, which was covered by seven concentration levels. Finally, precision and accuracy were established from spikes into authentic PM whole blood samples known to be negative for sartans. Whole blood samples were spiked at 30 and $300 \mathrm{ng} / \mathrm{mL}$, and three replicates were prepared. Precision was expressed as within sample RSD (Wi RSD) and between sample RSD (Bw RSD) of the determined concentrations, and was calculated from the calibration samples and from the spikes. Accuracy was expressed as trueness of the measured value compared to the theoretical value, and was also calculated from both calibration samples and spiked PM samples.

\section{Combined variation from matrix}

The overall matrix effect was studied by spiking 13 authentic PM whole blood samples with the sartans at concentrations of 30 and $300 \mathrm{ng} / \mathrm{mL}$. All of the $13 \mathrm{PM}$ samples were known to be negative for sartans, but were eventually found to contain other drugs. Three replicates for each spike were prepared. The Wi RSD was calculated as average RSD of peak areas or concentrations of the three replicates, whereas the Bw RSD was calculated from averaged peak areas or concentrations of the 13 PM samples. In comparison of Wi and Bw RSDs of the peak areas, a significantly higher Bw RSD than Wi RSD was tentatively regarded as an indication of the combined effects of matrix and variations in extraction efficiency [19]. Additionally, a statistical comparison of Wi and Bw RSDs was performed using one-way analysis of variance (ANOVA).

\section{Results and discussion}

\section{Validation results}

All validation results are summarized in Table 2. Selectivity was shown to be acceptable as no interfering peaks were detected (Fig. 1). Only minor signals for candesartan, losartan, and telmisartan were detected in just a few of the 40 tested samples, and in these cases the estimated concentrations were below the LLOQ. A linear regression of the calibration plot was not obtained because the calibration plots at concentrations higher than $300 \mathrm{ng} / \mathrm{mL}$ started to bend strongly. However, within the concentration range of $3-1000 \mathrm{ng} / \mathrm{mL}$, an excellent correlation $\left(R^{2}>0.999\right)$ 
Table 2 Summary of the validation results of the seven sartans

\begin{tabular}{|c|c|c|c|c|c|c|c|c|}
\hline \multirow[t]{2}{*}{ Compound } & \multicolumn{2}{|c|}{ Working range $(\mathrm{ng} / \mathrm{mL})$} & \multirow{2}{*}{$\begin{array}{l}\text { Cal plot } \\
\left(R^{2}\right)\end{array}$} & \multirow[t]{2}{*}{ Accuracy $(\%)$} & \multirow{2}{*}{$\begin{array}{l}\text { Precision of concentration } \\
(\mathrm{Bw} / \mathrm{Wi})\end{array}$} & \multicolumn{3}{|c|}{ Variation of peak areas and one-way ANOVA } \\
\hline & LLOQ & ULOQ & & & & $\mathrm{Bw} / \mathrm{Wi}$ & $p$ value & ME \\
\hline Candesartan & 5 & 1000 & 0.9995 & $105 \pm 2$ & $1.4 \pm 0.5$ & $1.6 \pm 0.2$ & $\geq 0.0001$ & No \\
\hline Eprosartan & 5 & 1000 & 0.9992 & $113 \pm 1$ & $1.9 \pm 0.4$ & $2.1 \pm 0.4$ & $<0.0001$ & Yes \\
\hline Losartan & 5 & 1000 & 0.9983 & $122 \pm 11$ & $1.6 \pm 0.0$ & $1.8 \pm 0.6$ & $<0.0001$ & Yes \\
\hline Olmesartan & 5 & 1000 & 0.9998 & $85 \pm 3$ & $1.7 \pm 0.8$ & $2.7 \pm 0.1$ & $<0.0001$ & Yes \\
\hline Telmisartan & 5 & 1000 & 0.9999 & $87 \pm 2$ & $3.0 \pm 0.9$ & $2.0 \pm 0.1$ & $<0.0001$ & Yes \\
\hline Valsartan & 5 & 1000 & 0.9998 & $109 \pm 7$ & $1.3 \pm 0.1$ & $1.4 \pm 0.4$ & $\geq 0.0001$ & No \\
\hline EXP3174 & 5 & 1000 & 0.9994 & $77 \pm 16$ & $1.0 \pm 0.2$ & $1.2 \pm 0.3$ & $\geq 0.0001$ & No \\
\hline
\end{tabular}

$L L O Q$ lower limit of quantitation, $U L O Q$ upper limit of quantitation, Wi relative standard deviation, $B w$ RSD between samples, $M E$ Matrix effect, EXP3174 the active metabolite of losartan, ANOVA analysis of variance

was obtained by using quadratic regression with $1 / x$ weighting. Therefore, the ULOQ was set to $1.0 \mathrm{mg} / \mathrm{L}$ for all compounds, and all routine samples with higher concentrations were diluted before the analysis. The LLOQ was set at $5 \mathrm{ng} / \mathrm{mL}$ for all compounds that fulfilled the criteria for accuracy and RSD. This was satisfactory when the lower therapeutic concentration for the sartans studied varied from 4 to $800 \mathrm{ng} / \mathrm{mL}$. Precision was expressed as Wi and Bw RSDs. The Wi RSD for all sartans ranged from 11 to $19 \%$, whereas Bw RSD varied from 15 to $26 \%$ in the calibration samples and spiked PM samples. Accuracy ranged between 98 and $100 \%$ for all compounds when calculated from the calibration plots. However, spiked PM blood samples showed that the concentrations obtained were too high for losartan (122\%), and too low for olmesartan (85\%), telmisartan (87\%), and EXP3174 (77\%). The accuracy of candesartan, eprosartan, and valsartan spikes was 105, 113, and $109 \%$, respectively.

Combined matrix effects were evaluated from the variation of peak areas of the spiked (at 30 and $300 \mathrm{ng} / \mathrm{mL}$ ) sartans in the 13 authentic PM samples. Comparison of the $\mathrm{Wi}$ and $\mathrm{Bw}$ RSDs of the peak areas revealed that the $\mathrm{Bw}$ RSD was from 1.2 (EXP3174) to 2.7 (olmesartan) times higher than Wi RSD. The difference between these two RSDs can be assumed to be due to matrix effects. When Wi and $\mathrm{Bw}$ RSDs were calculated using concentrations, the Wi/Bw RSD ratios ranged between 1.0 (EXP3174) and 3.0 (telmisartan) (Table 2). The results obtained previously in another study that used a standard addition method for metformin analysis [19], indicate a matrix effect in the analytical method when the $\mathrm{Wi} / \mathrm{Bw}$ RSD ratio for the peak area is about two or higher. On the other hand, when the ratio for the concentrations is below two, it indicates that a sufficient compensation of the matrix effect through a proper calibration method had occurred, such as using an internal standard or standard addition method. Based on the results obtained, a matrix effect was observed for three sartans, but it was satisfactorily compensated using the internal standard. Statistical calculations that use ANOVA revealed that the matrix effect was very significant $(p<0.0001)$ for four of the seven sartans, which is in accordance with the $\mathrm{Wi} / \mathrm{Bw}$ ratio results. Despite of the observed matrix effect, the method was considered to be adequately precise because Wi RSD was less than $19 \%$ and $\mathrm{Bw}$ RSD less than $26 \%$ for all sartans even in the spiked PM samples. Furthermore, the accuracy ranged from 77 to $122 \%$, which can be considered acceptable for this kind of analysis. Some of the samples used for validation were putrid but we did not observe any significant effect of putrefaction on the recovery or precision of the compounds.

\section{Postmortem concentrations}

Table 3 shows the characteristics of the sartans studied (volume of distribution $V_{d}$ and therapeutic range) together with measured concentrations (the concentration range, median, and mean concentration). The number of positive findings for different compounds ranged from one for eprosartan to 304 for losartan, which accounted for $57 \%$ of all positive cases (534 total), whereas the total number of samples analyzed was 652 , producing a negative result in 118 cases. The number of positive findings for EXP3174 is much lower than that for losartan because EXP3174 was added to the method later on in the experimental period than the parent compound. Sartans were analyzed only when a sartan was mentioned in the medication of the deceased person or a positive finding was observed from a urine sample using a qualitative ultra-high performance liquid chromatography-quadrupole time-of-flight mass spectrometric (UHPLC-QTOF/MS) method.

There were nine cases where the concentration of a sartan clearly exceeded the therapeutic range and also the normal concentrations obtained from PM blood (Table 4). Cases one, two, and seven were regarded as a fatal overdose of other drugs, but a sartan also contributed to the 
Table 3 Characteristics of the seven sartans for non-fatal authentic cases

\begin{tabular}{|c|c|c|c|c|c|c|c|}
\hline \multirow[t]{2}{*}{ Compound } & \multirow[t]{2}{*}{$\begin{array}{l}\text { Cases } \\
(n)\end{array}$} & \multirow[t]{2}{*}{$\begin{array}{l}\mathrm{V}_{\mathrm{d}}(\mathrm{L} / \mathrm{kg}) \\
\text { [reference] }\end{array}$} & \multirow[t]{2}{*}{$\begin{array}{l}\text { Therapeutic range }(\mathrm{ng} / \mathrm{mL}) \\
\text { [reference] }\end{array}$} & \multicolumn{3}{|c|}{$\begin{array}{l}\text { Measured concentrations } \\
(\mathrm{ng} / \mathrm{mL})\end{array}$} & \multirow[t]{2}{*}{$\begin{array}{l}\text { Within therapeutic range } \\
(\%)\end{array}$} \\
\hline & & & & Range & Median & Mean & \\
\hline Candesartan & 73 & $0.13[20]$ & $80-180[21]$ & $5-680$ & 48 & 87 & 86 \\
\hline Eprosartan & 1 & $0.15-0.21[20]$ & $400-1850[21]$ & 5 & 5 & 5 & 100 \\
\hline Losartan & 304 & $0.2-0.6[20]$ & $<650[21]$ & $5-7500$ & 60 & 195 & 94 \\
\hline Olmesartan & 3 & $0.2-0.3[20]$ & $<3000[22]$ & $60-100$ & 71 & 78 & 100 \\
\hline Telmisartan & 45 & $6.6-7.6[20]$ & $<5000[23]$ & $5-3400$ & 210 & 353 & 100 \\
\hline Valsartan & 46 & $0.14-0.34[20]$ & $800-6000[21]$ & $5-14,000$ & 275 & 1510 & 94 \\
\hline EXP3174 & 62 & $-\mathrm{a}$ & $<600[24]$ & $5-4400$ & 89 & 259 & 90 \\
\hline
\end{tabular}

poisoning, especially in case one in which the concentration of losartan was extremely high $(7500 \mathrm{ng} / \mathrm{mL})$. The concentration of losartan in case three was also very high $(2500 \mathrm{ng} / \mathrm{mL})$ and in combination with a high concentration of ethanol $(1.3 \mathrm{mg} / \mathrm{mL})$ was regarded as death by intoxication of both ethanol and losartan. The concentrations of losartan and trimethoprim in case four were three to four times that of the respective therapeutic range, but the actual cause of death was heart disease in the 81-yearold woman. The person in case five suffered from hepatosteatosis, which might have elevated the concentrations of losartan and its metabolite EXP3174. There was a suspicion of temazepam poisoning in case six and acebutolol poisoning in case eight. The overall analytical findings revealed, however, multidrug poisoning with ethanol, warfarin, temazepam, and candesartan for case six and acebutolol, paracetamol, and valsartan poisoning for case eight. The deceased in case nine had a cyst in his liver and suffered from coronary artery disease, additionally the concentration of amlodipine, a calcium channel blocker, was clearly higher in his blood than expected for the therapeutic range and the usual concentrations in PM blood [25]. Furthermore, the deceased was putrid, which might have resulted in elevated concentrations in the blood due to diffusion from organs. However, the case was considered to be a toxic/fatal overdose of both amlodipine and valsartan.

PM redistribution of drugs can have a large effect on the whole blood concentrations [26]. The volumes of distribution $\left(V_{d}\right)$ for sartans (Table 3) are low or moderate except for telmisartan, thus they should not affect the PM blood concentrations in most situations. This suggestion can be born out for all sartans studied, as the mean and median values for PM blood concentrations are well below the upper limit of the therapeutic range, and this is also the case for telmisartan, which has a high $V_{d}$ value (Table 3 ). In total, $93.3 \%$ of the concentrations measured were within the therapeutic range, and most of the exceeding values were just above the upper limit of the therapeutic range. Some of the samples were slightly or extensively putrid, but we did not observe any direct correlation between the concentrations and the states of putrefaction. Protein binding of all sartans is very high $(>95 \%)$ and blood/plasma ratios are 0.5-0.6 [20], but these factors did not affect the PM blood concentrations, based on our results. Therefore, the therapeutic ranges could be used for the evaluation of possible toxic or fatal concentrations in PM blood. The data obtained also give evidence that poisoning by sartans is rare, but clear overdose cases were found based on their concentrations found in the PM blood.

\section{Conclusions}

A new LC-MS/MS method was developed and validated for the analysis of seven common sartans (candesartan, eprosartan, losartan, EXP3174 the active metabolite of losartan, olmesartan, telmisartan, and valsartan) in PM blood samples using a two-step liquid-liquid extraction and detection by using a triple-quadrupole instrument in the SRM mode setting. The method shows some matrix effect, but the effect was efficiently compensated by the use of internal standards, and the method subsequently produced accurate and precise analytical results. The method was applied to the analysis of PM blood samples, and it produced 534 positive findings, nine concentrations of which clearly exceeded the therapeutic range. The quantitative results indicate that sartans do not show 


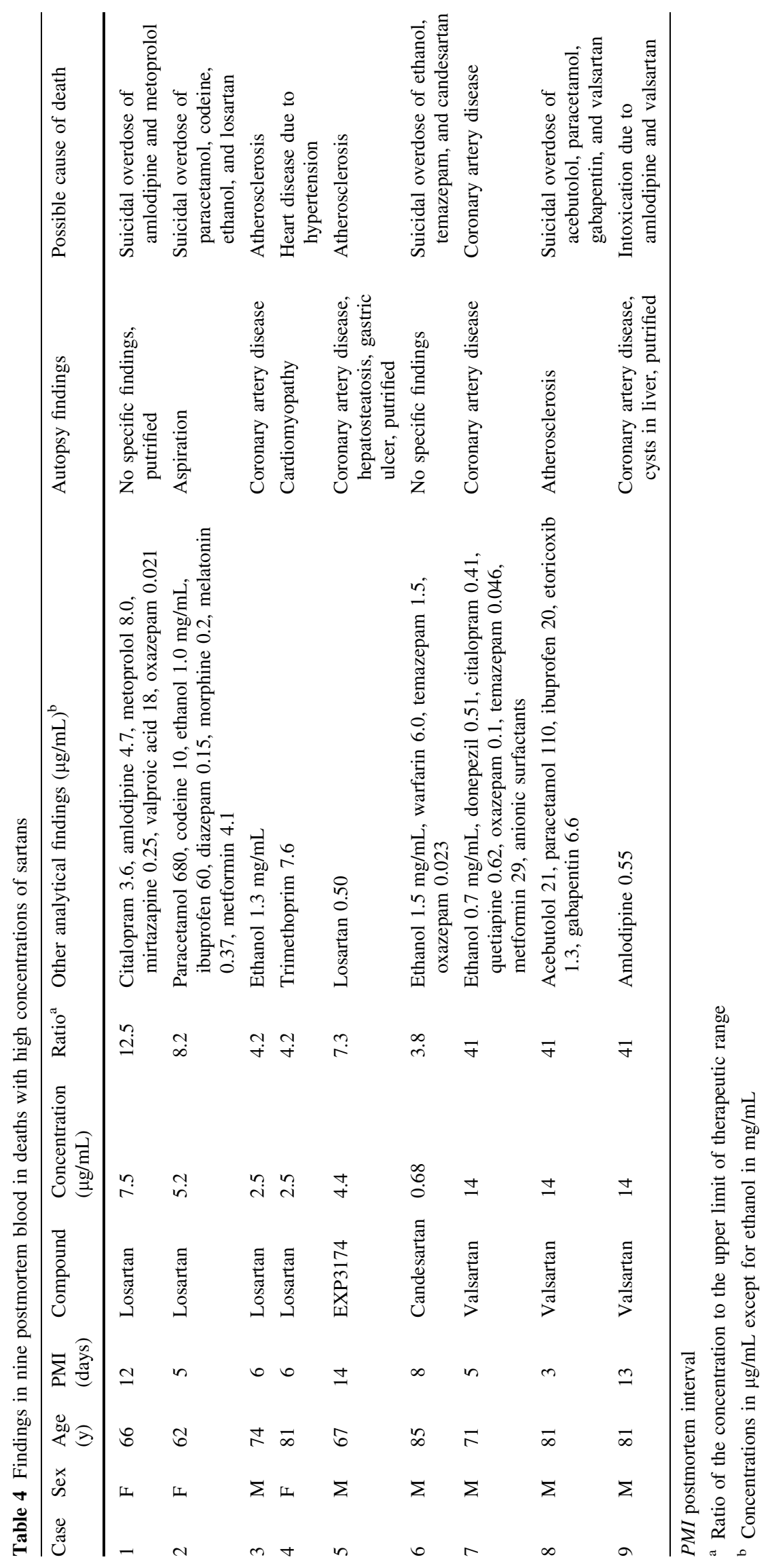


significant PM redistribution, thus concentrations found to be higher than the therapeutic range can be considered as being toxic or fatal concentrations.

\section{Compliance with ethical standards}

Conflict of interest There are no financial or other relations that could lead to a conflict of interest.

Ethical standards This article does not contain any studies with living human participants or animals performed by any of the authors. The analysis of drugs from the autopsy specimens was performed according to the request of judicial authorities.

\section{References}

1. Ryan MR, Didion SP, Mathur S, Faraci FM, Sigmund CD (2004) Angiotensin II-induced vascular dysfunction is mediated by the AT1A receptor in mice. Hypertension 43:1074-1079

2. Sharma AM, Janke J, Gorzelniak K, Engeli S, Luft FC (2002) Angiotensin blockade prevents type 2 diabetes by formation of fat cells. Hypertension 40:609-611

3. Ahmad S (1996) Losartan and reversible psychosis. Cardiology 87:569-570

4. Bosch X (1997) Losartan-induced hepatotoxicity. J Am Med Assoc 278:1572

5. Celentano C, Prefumo F, di Vera E, Iannicco A, Pio Gallo D, Liberati M (2008) Reversible acute fetal renal failure due to maternal exposure to angiotensin receptor blocker. Pediatr Nephrol 23:333-334

6. Forrester MB (2007) Valsartan ingestions among adults reported to Texas Poison Control Centers, 2000-2005. J Med Toxicol 3:157-163

7. Jang DH, Nelson LS, Hoffman RS (2011) Use of naloxone and vasopressin to treat prolonged hypotension following valsartan overdose. Abstracts of the 2011 International Congress of the European Association of Poisons Centres and Clinical Toxicologists, 24-27 May 2011, Dubrovnik, Croatia. Clin Toxicol 49:209

8. Baffoni L, Durante V (2004) Acute pancreatitis induced by telmisartan overdose. Ann Pharmacother 38:1088

9. Muszalska I, Sobczak A, Dołhań A, Jelińska A (2014) Analysis of sartans: a review. J Pharm Sci 103:2-28

10. González L, Alonso RM, Jiménez RM (2000) A high-performance liquid chromatographic method for screening angiotensin II receptor antagonists in human urine. Chromatographia 52:735-740

11. González L, López JA, Alonso RM, Jiménez RM (2002) Fast screening method for the determination of angiotensin II receptor antagonists in human plasma by high-performance liquid chromatography with fluorimetric detection. J Chromatogr A 949:49-60

12. Gonzalez O, Alonso RM, Ferreirós N, Weinmann W, Zimmermann R, Dresen S (2011) Development of an LC-MS/MS method for the quantitation of 55 compounds prescribed in combined cardiovascular therapy. J Chromatogr B 879:243-252
13. Nie J, Zhang M, Fan Y, Wen Y, Xiang B, Feng TQ (2005) Biocompatible in-tube solid-phase microextraction coupled to HPLC for the determination of angiotensin II receptor antagonists in human plasma and urine. J Chromatogr B 828:62-69

14. Ferreirós N, Iriarte G, Alonso RM, Jiménez RM (2007) Development of a solid phase extraction procedure for HPLC-DAD determination of several angiotensin II receptor antagonists in human urine using mixture design. Talanta 73:748-775

15. Ferreirós N, Dresen S, Alonso RM, Weinmann W (2007) Validated quantitation of angiotensin II receptor antagonists (ARA-II) in human plasma by liquid-chromatography-tandem mass spectrometry using minimum sample clean-up and investigation of ion suppression. Ther Drug Monit 29:824-834

16. Ferreirós N, Iriarte G, Alonso RM, Jiménez RM, Ortíz E (2008) Separation and quantitation of several angiotensin II receptor antagonist drugs in human urine by a SPE-HPLC-DAD method. J Sep Sci 31:667-676

17. Brunetto MR, Contreras Y, Clavijo S, Torres D, Delgado Y, Ovalles F, Ayala C, Gallignani M, Estela JM, Martin VC (2009) Determination of losartan, telmisartan, and valsartan by direct injection of human urine into a column-switching liquid chromatographic system with fluorescence detection. J Pharm Biomed Anal 50:194-199

18. Kristoffersen L, Øiestad EL, Opdal MS, Krogh M, Lundanes E, Christophersen AS (2007) Simultaneous determination of 6 betablockers, 3 calcium-channel antagonists, 4 angiotensin-II antagonists and 1 antiarrhytmic drug in post-mortem whole blood by automated solid phase extraction and liquid chromatography mass spectrometry: method development and robustness testing by experimental design. J Chromatogr B 850:147-160

19. Gergov M, Nenonen T, Ojanperä I, Ketola RA (2015) Compensation of matrix effects in a standard addition method for metformin in postmortem blood using liquid chromatographyelectrospray-tandem mass spectrometry. J Anal Toxicol 39:359-364

20. Baselt BC (2014) Disposition of toxic drugs and chemicals in man, 10th edn. Biomedical Publications, Seal Beach

21. Schulz M, Iwersen-Bergmann S, Andresen H, Schmoldt A (2012) Therapeutic and toxic blood concentrations of nearly 1,000 drugs and other xenobiotics. Crit Care 16:R136

22. Laeis P, Püchler K, Kirch W (2001) The pharmacokinetic and metabolite profile of olmesartan medoxomil limits the risk of clinically relevant drug interaction. J Hypertens 19(suppl 1):S21S32

23. Stangier J, Su CAPF, Roth W (2000) Pharmacokinetics of orally and intravenously administered telmisartan in healthy young and elderly volunteers and in hypertensive patients. J Int Med Res 28:149-167

24. Kazierad DJ, Martin DE, Bhun RA, Tenero DM, Ilson B, Boike SC, Etheredge R, Jorkasky DIL (1997) Effect of fluconazole on the pharmacokinetics of eprosartan and losartan in healthy male volunteers. Clin Pharmacol Ther 62:417-425

25. Launiainen T, Ojanperä I (2014) Drug concentrations in postmortem femoral blood compared with therapeutic concentrations in plasma. Drug Test Anal 6:308-316

26. Pélissier-Alicot AL, Gaulier JM, Champsaur P, Marquet P (2003) Mechanisms underlying postmortem redistribution of drugs: a review. J Anal Toxicol 27:533-544 